\title{
HOW CUSTOMER EQUITY DRIVERS AFFECT BEHAVIORAL INTENTIONS AND BEHAVIOR OVER TIME: AN EMPIRICAL ASSESSMENT
}

\author{
Heiner Evanschitzky, Aston University, UK \\ Alexander Eiting, TU Dortmund University, Germany \\ David M. Woisetschläger, TU Braunschweig University, Germany \\ Verena Richelsen, Bayer Business Services, Germany
}

\begin{abstract}
There is a strongly held belief that if companies can direct their marketing activities to improve customer attitudes and intentions, it will impact on purchase behaviors. Departing from complementary yet sometimes conflicting findings of the current literature, we intend to contribute to the literature by answering two related questions. First, we investigate drivers of loyalty intention over time, and by so doing try to better understand loyalty formation. Second, once we understand loyalty formation, we assess the impact of loyalty on different aspects of purchase behavior, considering temporal effects. Therefore, we develop a consumption-system model which assumes that perceptions, intention, and the impact of perceptions and intention on behavior in one period serve as anchors for the same constructs in a subsequent period, implying a pattern of repeated consumption over time.
\end{abstract}

Using 3SLS regression analysis, results of a large-scale study using survey data from a sample of 2,478 customers from two points in time and purchase data gathered over a 30-month period suggest interesting findings on the two aforementioned questions:

Considering the first question, we find strong support for customer equity drivers directly influencing loyalty. Moreover, we see evidence for loyalty formation as a consumption-system as equity drivers and loyalty intention of one period are significant predictors of the same constructs in the next period.

Addressing the second research question is less straightforward. We find a significant impact of loyalty intention only for purchase frequency, but not for future sales and average receipt. This suggests that in a retailing context, the amount spent depends to a larger extent on actual needs and not on loyalty intention. Loyalty intention seems to be a more appropriate lead indicator for the frequency of store visits. For most categories, repurchase intention will not necessarily be related to higher sales. On the contrary, higher future sales are more likely to depend on the retailer's ability to cross- and up-sell to its customers. In all, we need to acknowledge that the strongest predictor of future behavior is, in fact, past behavior.

These results question some of the strongly held beliefs of relationship marketing and its impact on actual behavior. Effects might not be as simple as they appear at first, i.e., temporal interplay between constructs. Moreover, it seems that inertia is more important than some marketing research tends to acknowledge. We would therefore suggest a more detailed investigation of customers' initial choice behavior. If, in fact, inertia is the driving force behind purchase behavior, companies need to augment their emphasis on increasing initial customer contact and, accordingly, on initial product trial. This is somewhat counter-intuitive from a relationship marketing perspective, because that stream of research largely suggests the advantage of retaining customers rather than acquiring new ones. While we are not denying the importance of customer retention, it seems that companies are already fairly successful in doing so - the strong inertia effect confirms that. Hence, customer retention might not be the best strategy to differentiate in the market. Perhaps companies can better differentiate by excelling in customer acquisition. This, however, would have a significant impact on how marketing budgets should be spent by companies trying to reach sustained success. It might be time for re-balancing customer acquisition and customer retention.

References Available on Request. 